of social medicine. Social science workers would be helped by such instruction, and in extra-mural university classes and in adult education such teachers could play an important part.

To provide these teachers it will be necessary for the universities to increase the number of students taking honours courses in physiology, but who are not going on to medicine. It will also be necessary for the various educational institutions to realize the value of having on their staffs teachers so trained.

In schools, broadcasting and films can be useful aids, though they in no way lessen the responsibility of the class-room teacher, from whom the main inspiration must always come. In preparing such aids it is necessary to have co-operation between three sets of experts, the class-room teacher and the experts in the subject and in the medium to be used. It is necessary, too, for teachers to have training in the of such use aids.

It is Prof. Cullis's firm conviction that this wider teaching of physiology would result in a better understanding of various problems intimately associated with healthy living, so leading to a higher and better standard of health for the individual.

\section{MAN'S ADAPTABILITY}

$\mathrm{T}$ $H E$ question of the adaptability of man was the theme of Dr. S. J. F. Philpott's address before Section $J$ (Psychology). Many of the problems psychologists have handled during the War and that will face them during the peace have had to do with man's adaptability. Can a bank clerk be changed, almost overnight, into a tank gunner ? Can he be changed back by a stroke of the pen?

If the doctrine of round pegs in round holes were strictly true such transformations would be difficult, if not impossible. In practice, they can take place with surprising ease, especially if the will to act is present. There are limits. Broadly speaking, men are only adaptable within the limits of their all-round ability; but granted the will and the ability, man can play many parts.

In asking just how an individual is equipped and just how he can adapt himself, we must realize that he works as a whole. When in the workshop planing or sawing a piece of wood, it is my body as a whole that I use, throwing it now into the attitude appropriate to the use of a plane, now into the attitude appropriate to the use of a hand saw. I do not use a planing organ or a sawing organ.

In similar fashion, I am now in the mental attitude appropriate to making an abstract. In a moment I may be in the frame of mind appropriate to making some calculations, or writing a letter, and so on. It is my mind as a whole that I use in each of these operations. I do not use an abstracting organ or a calculating organ.

The problem of education into a given culture is that of giving the individual an enormous number of such attitudes, skills or techniques, ranging from the simplest of everyday actions like opening doors up to the highest expression of the arts and sciences. We only begin to realize the significance of the complex of skills thus built up when we learn about 'wolf children' realizing how much they have lost. Yet no matter how complex the result of all this training, it still remains that all activities can be traced to the functioning of the one general-purposes body-mind instrument.

The problem of drill arises whether in peace or war. It is that of making these various techniques automatic. One cannot enjoy riding a bicycle until all movements of hands and feet and body take place well below the conscious level. No.man can be master of his craft until he has made himself a slave to the minor habits involved, the fingering of his instrument or the handling of his tools.

Before advising training, we often to-day apply tests of potentiality. The naive view is that we ought to be able to devise tests to distinguish between those born to be tank gunners and those born to be tank drivers. In fact, a one-time carpenter can often succeed at either of the other two occupations. Granted that at the moment he knows nothing about either of them, will tests for potential drivers or potential gunners pick him out? If so, will it not be a case of a test for drivers picking out a potential gunner? Or so far as that goes, will it not have picked out an actual carpenter ? Put briefly, although it is easy to devise tests of all-round ability (trainability or adaptability) it is quite another matter to discover tests that shall assess potentiality in respect of some one occupation and it alone. There is wide overlap. The bearing of this on problems of peace, such as that of advising children into the best form of education, is obvious.

\section{THE HISTORY OF PLANT FORM}

$\mathrm{A}$ LTHOUGH in recent years botanists have been mainly interested in the study of growing plants, many of their generalizations are based on a belief that evolution has taken place in the plant world. But since very little historical evidence of the evolu. tion of the flowering plants has been forthcoming, this belief has become a dogma, maintained in spite of the absence of proof. This unsatisfactory position, said Dr. H. Hamshaw Thomas, in his presidential address to Section K (Botany), warrants a survey of our present knowledge of the fossil record.

Past failure to find any clues to the early history of the flowering plants may be due to a deductive examination of the evidence. The logical basis of evolutionary study is different from that of pure or typological morphology, but it has been assumed that the Urform of the pure morphologist represents the primitive type of flowering plant. Consequently we may have been searching for structures which have never existed. The actual record of changes in plant form through the ages suggests the evolution of the angiosperms through types very different from those imagined.

The geological record becomes clearer if we com. pare the plant forms from successive terrestrial periods, dividing the geological time-scale in a manner complementary to the normal classification of strata, the groups of which represent periods of marine sedimentation. Owing to the rare conditions under which plants are preserved as fossils, we can never hope to trace real phylogenies, but we can obtain evidence of the ways in which structures have changed in the past 400 million years.

The remains of the Upper Silurian-Lower Devonian land plants show forms widely different from the plants of to-day. Types with smooth forking axes predominated; they had little differentiation into 